\title{
Gender Differences in the Presentation of Adult Obstructive Hypertrophic Cardiomyopathy With Resting Gradient
} A Study of 122 Patients

\author{
Chin-Lon Lin, MD*; Cheng-Wen Chiang, MD; Cheng-Kuang Shaw, DR PH; \\ Po-Hsien Chu, MD; Chi-Jen Chang, MD; Yu-Lin Ko, MD
}

\begin{abstract}
The present study investigated gender differences among adult patients with obstructive hypertrophic cardiomyopathy $(\mathrm{OHCM})$ and resting gradient. Using outflow gradients $>10 \mathrm{mmHg}$ and the presence of asymmetrical septal hypertrophy of the left ventricle as inclusion criteria, 122 patients were identified among patients referred for echocardiographic examinations between May 1990 and October 1996. Clinical, echocardiographical and follow-up data were compared between male and female patients. The female patients were significantly older than male patients (mean age \pm SD $66.7 \pm 10.5$ vs $54.8 \pm 12.5$ years). The female patients had a smaller interventricular septal wall thickness, less frequent systolic anterior movement of the mitral valve, more frequent association with hypertension, and less frequent association with ischemic heart disease (IHD) and giant T wave inversion. In this study population, adult female patients presented with OHCM 12 years later than males. Whether this represents female patients' reluctance to seek medical attention early, a different disease process that affects predominantly elderly females, or a gender-specific end organ response to aging, hypertension, IHD and other processes, or the protective effects of estrogen remains to be determined. (Jpn Circ J 1999; 63: 859-864)
\end{abstract}

Key Words: Cardiomyopathy; Echocardiography; Gender; Hypertrophy

$\mathbf{T}$ he natural history of hypertrophic cardiomyopathy (HCM) has been described in many large studies ${ }^{1-4}$ However, gender differences among patients with obstructive hypertrophic cardiomyopathy (OHCM) have rarely been systemically analyzed. The present study attempted to define these differences in terms of clinical presentation, echocardiographic manifestation and outcome among adult patients with OHCM.

\section{Methods}

The hospital in which the study took place is a university-affiliated tertiary referral hospital in suburban Taipei, and the department receives patients from both inpatient wards and outpatient clinics. A total of 122 cases of $\mathrm{OHCM}$ were identified using the criteria of a peak systolic gradient of $>10 \mathrm{mmHg}$ (or a velocity of $>1.6 \mathrm{~m} / \mathrm{s}$ ) in the left ventricular outflow tract(LVOT $)^{5}$ and the presence of asymmetrical hypertrophy of the interventricular septum (IVS) (interventricular septal wall thickness/left ventricular posterior wall thickness $>1.3$ ). We included patients with a history of hypertension if they met these criteria. Their clinical profiles, such as age, gender, presenting symptoms, ECG and chest X-ray findings, current medications, echocardiographic and Doppler measurements, were

(Received April 15, 1999; revised manuscript received June 28, 1999; accepted July 23, 1999)

First Cardiovascular Division, Department of Internal Medicine, Chang Gung Memorial Hospital, Chang Gung University, *Cardiology Division, Department of Internal Medicine, The Buddhist Tzu-Chi General Hospital and **Department of Public Health, Tzu-Chi Medical College, Taiwan, Republic of China

Mailing address: Cheng-Wen Chiang, MD, Chang Gung Memorial Hospital, 199 Tunghwa North Road, Taipei, Taiwan, R.O.C. E-mail: cwchiang@adm.cgmh.com.tw analyzed and follow-up data were obtained by either checking the hospital records or mailing a questionnaire to patients, followed by a telephone interview if the questionnaire was not returned within 10 days of mailing. In addition, to validate the completeness of follow-up, the patients' personal unique identification numbers were checked with the national death certificate registry to confirm those who died during the study period and the reported primary causes of death.

\section{Echocardiographic Examination}

Two-dimensional echocardiograms and Doppler studies were performed using a commercially available HewlettPackard 1500 or 2500 ultrasonic system equipped with a $2.5 \mathrm{MHz}$ transducer, and 2-dimensional images were obtained in standard transducer positions (parasternal longand short-axes and apical 2- and 4-chamber views). Mmode echocardiograms were derived from the 2-dimensional images. Cardiac dimensions were measured from Mmode echocardiograms according to the recommendations of the American Society of Echocardiography? Left ventricular outflow tract pressure gradients were estimated by the modified Bernoulli equation (4times the square of the maximal velocity in the left ventricular outflow tract). Five minutes after sublingual administration of $0.6 \mathrm{mg}$ of nitroglycerin, pressure gradient measurements were repeated.

\section{Statistical Methods}

The collected data was then tabulated and analyzed using BMDP Dynamic Release 7.0 (BMDP Statistical Software 1990. Los Angeles, CA, USA) All continuous variables were expressed as mean \pm standard deviation (SD). Univariate analyses using 2-tailed Student's t-test and chi-square tests were performed. A $p$ value of $<0.05$ 
Table 1 Gender differences in Baseline Clinical Presentation, Electrocardiogram, ChestX-ray, Echocardiographic Findings, Medications and Mortality During Follow-up

\begin{tabular}{|c|c|c|c|}
\hline & Male $(n=46)$ & Female $(n=76)$ & p-value \\
\hline Age (year) & $54.8 \pm 12.5$ & $66.7 \pm 10.5$ & $0.0000 *$ \\
\hline Syncope & $9 / 56(19.6 \%)$ & $21 / 76(27.6 \%)$ & 0.3160 \\
\hline Chest pain & $18 / 46(39.1 \%)$ & $33 / 76(43.4 \%)$ & 0.6415 \\
\hline Family history & $0 / 46(0.0 \%)$ & $1 / 76(1.3 \%)$ & 1.0000 \\
\hline Hypertension & $17 / 46(37.0 \%)$ & $44 / 76(57.9 \%)$ & $0.0250 *$ \\
\hline Diabetes mellitus & $1 / 46(2.2 \%)$ & $5 / 76(6.6 \%)$ & 0.5102 \\
\hline Ischemic heart disease & $7 / 46(15.2 \%)$ & $1 / 76(1.3 \%)$ & $0.0086 *$ \\
\hline Palpitation & $10 / 46(21.7 \%)$ & $10 / 76(13.2 \%)$ & 0.2147 \\
\hline Congestive heart failure & $10 / 46(21.76 \%)$ & $14 / 76(18.4 \%)$ & 0.6550 \\
\hline Left ventricular hypertrophy (By ECG) & $24 / 46(54.3 \%)$ & $34 / 76(44.7 \%)$ & 0.3032 \\
\hline$Q$ waves on $E C G$ & $4 / 46(8.7 \%)$ & $7 / 76(9.2 \%)$ & 0.9233 \\
\hline Giant $T$ waves & $11 / 46(23.9 \%)$ & $4 / 76(5.3 \%)$ & $0.0059 *$ \\
\hline Atrial fibrillation & $4 / 46(8.7 \%)$ & $11 / 76(14.5 \%)$ & 0.5109 \\
\hline Ventricular ectopy & $6 / 46(13.0 \%)$ & $4 / 76(5.3 \%)$ & 0.2389 \\
\hline Ventricular tachycardia & $2 / 46(4.3 \%)$ & $3 / 76(3.9 \%)$ & 1.0000 \\
\hline Cardiomegaly on X-ray & $31 / 46(67.4 \%)$ & $51 / 76(67.1 \%)$ & 0.9740 \\
\hline Congestion on X-ray & $6 / 46(13.0 \%)$ & $18 / 76(23.7 \%)$ & 0.1519 \\
\hline IVSt & $23.4 \pm 6.2$ & $21.4 \pm 4.9$ & $0.0435 *$ \\
\hline$L V P W t$ & $11.6 \pm 3.8$ & $10.4 \pm 2.3$ & 0.0628 \\
\hline$I V S t / L V P W t$ & $2.1 \pm 0.7$ & $2.1 \pm 0.6$ & 0.8299 \\
\hline VLVOT & $3.1 \pm 1.0$ & $3.1 \pm 1.1$ & 0.6436 \\
\hline$\triangle P L V O T$ & $41.1 \pm 27.1$ & $44.1 \pm 29.8$ & 0.5801 \\
\hline LADs & $30.0 \pm 9.90$ & $31.5 \pm 11.2$ & 0.2102 \\
\hline$V_{L V O T}[$ post $N T G]$ & $3.7 \pm 1.0$ & $3.9 \pm 1.2$ & 0.1803 \\
\hline$\Delta P_{\text {LVOT }}[$ post $N T G]$ & $56.9 \pm 29.7$ & $68.0 \pm 41.5$ & 0.0891 \\
\hline$S A M$ & $36 / 46(78.3 \%)$ & $36 / 76(47.4 \%)$ & $0.0008 *$ \\
\hline Mitral regurgitation & $3 / 46(6.5 \%)$ & $5 / 75(6.7 \%)$ & 0.9752 \\
\hline Beta-blockers & $21 / 46(45.7 \%)$ & $24 / 76(31.6 \%)$ & 0.1184 \\
\hline Calcium channel blockers & $20 / 46(43.5 \%)$ & $28 / 76(36.8 \%)$ & 0.4671 \\
\hline Norpace & $1 / 46(2.2 \%)$ & $1 / 76(1.3 \%)$ & 1.0000 \\
\hline Digitalis & $1 / 46(2.2 \%)$ & $8 / 76(10.5 \%)$ & 0.1760 \\
\hline Diuretics & $3 / 46(6.5 \%)$ & $11 / 76(14.5 \%)$ & 0.2972 \\
\hline$A C E I$ & $4 / 46(8.7 \%)$ & $3 / 76(3.9 \%)$ & 0.4894 \\
\hline Mortality during follow-up & $6 / 46(13.0 \%)$ & $12 / 76(15.8 \%)$ & 0.6785 \\
\hline
\end{tabular}

IVSt, thickness of the interventricular septum; LVPWt, thickness of the left ventricular posterior wall; VLVOT, velocity across left ventricular outflow tract; $\triangle P L V O T$, pressure gradient across left ventricular outflow tract; LADs, left atrial diameter at endsystole; NTG, nitroglycerin; SAM, systolic anterior movement of the mitral valve. LVH, Left ventricular hypertrophy; ACEI, angiotensin converting enzyme inhibitors.

* Statistically significant.

was considered statistically significant.

\section{Results}

The study group consisted of 122 patients (36\% male and $64 \%$ female). The mean age at the time of diagnosis was $61.5 \pm$ years (range, 16-85). The average follow-up period was 3.2 years. Most patients remained stable during the follow-up period from the cardiac point of view, with only a few reported new manifestations such as syncope (3 patients), palpitation (5 patients), chest pain (7 patients), and worsening of dyspnea (23 patients). During the followup period, there were 4 cardiac deaths and 14 deaths due to other causes such as diabetes mellitus (4 patients), liver diseases ( 3 patients), cerebrovascular diseases ( 2 patients), sepsis (2 patients), pneumonia, colon carcinoma, and renal failure (one patient each). The gender differences in baseline data are listed in Table 1; that is, clinical characteristics such as age, syncope, chest pain, family history, hypertension, diabetes mellitus, ischemic heart disease (IHD), palpitation, and congestive heart failure; electrocardiographic findings such as left ventricular hypertrophy, pathological $\mathrm{Q}$ waves, giant $\mathrm{T}$ waves, atrial fibrillation, ventricular ectopy, and ventricular tachycardia; chest X-ray findings such as cardiomegaly, pulmonary congestion; echocardiographic findings such as interventricular septal wall thick- ness (IVSt), left ventricular posterior wall thickness (LVPWt), Doppler velocity and pressure gradient across left ventricular outflow tract at rest (VLVOT, and $\triangle$ PLVOT ) and after sublingual nitroglycerin (VLVOT[post NTG] and $\Delta$ PLVot[post NTG]), left atrial dimension at end systole (LADs), systolic anterior movement of mitral valve (SAM), mitral regurgitation; the use of medications such as $\beta$-blockers, calcium channel blockers, disopyramide (Norpace), digitalis, diuretics, angiotensin converting enzyme inhibitors (ACEI); and mortality during the followup period. There were statistically significant gender differences in several variables. Female patients were much older than male (mean age \pm SD; $66.7 \pm 10.5$ vs $54.8 \pm 12.5$ years, $\mathrm{p}<0.0001$ ). The IVSt of male patients was larger than that of female patients $(23.4 \mathrm{~mm}$ vs $21.4 \mathrm{~mm}, \mathrm{p}=0.0435)$. Male patients had significantly more SAM, giant $\mathrm{T}$ wave inversion, and IHD, but less association with hypertension than female patients. There were no statistically significant gender differences among the other variables.

\section{Discussion}

Features of This Study

Gender differences in patients with OHCM have rarely been systemically analyzed; a literature search yielded only a few articles focusing only on a few items (Table2). Male 
Table 2 Gender Differences in Patients With Hypertrophic Cardiomyopathy

\begin{tabular}{ll}
\hline \hline Studies & Gender differences \\
\hline Brugada $^{7}$ & More LVH in male \\
Russel $^{8}$ & Less stroke risk in male \\
Aurigemma $^{9}$ & Elderly female with aortic stenosis developed more LVH \\
Pelliccia $^{10}$ & Atheletic training was a stimulus for LVH in male but not in female \\
Maron $^{l 1}$ & Sudden death on the athletic field is uncommon in young women \\
Dimitrow $^{12}$ & Delayed onset of symptoms in women with HCM compared with men. \\
Present study $^{\text {Male patients were younger, had thicker IVS, more negative giant Twave, more ischemic heart }}$ \\
& disease, and less hypertension. \\
\hline
\end{tabular}

Abbreviations: As in Table 1.

patients had more left ventricular hypertrophy $(\mathrm{LVH})$ and gender accounted for $4.8-5.4 \%$ of the variability of the phenotypic expression of $\mathrm{LVH}$ in patients with $\mathrm{HCM}^{7}$; although female gender was associated with an increased risk of stroke in patients with $\mathrm{HCM}^{8}$, elderly females with aortic stenosis developed more marked concentric $\mathrm{LVH}^{9}$; athletic training was not a stimulus for LVH in women athletes as opposed to male athletes ${ }^{10}$ and sudden death on the athletic field is uncommon in young women ${ }^{11}$; women with HCM had a delayed onset of symptoms compared with men!2 Our study, through systematic analyses, revealed the following gender differences: the male patients were younger, had thicker IVS, more giant negative T waves, SAM and IHD, but less hypertension. However, it should be pointed out that, our patients represented a subset of OHCM patients with a resting LVOT gradient, therefore the data and interpretation may not be applicable to all OHCM patients. We believe that the presence of a resting LVOT gradient might be more specific than the presence of SAM, because the latter can occur in cases with redundant mitral valve, which is by no means rare in the elderly population. Of course, the adoption of resting rather than provoked gradient as one of the inclusion criteria would improve specificity, but decrease sensitivity. We believe these findings might shed light on the pathophysiology and progression of OHCM as discussed next.

\section{Interventricular Septal Wall Thickness}

In the present study, the male patients had significantly thicker IVS $(23.4 \pm 6.2$ vs $21.4 \pm 4.9 \mathrm{~mm}, \mathrm{p}=0.0435)$ and thicker, though not statistically significant, LVPW (11.6 \pm 3.8 vs $10.4 \pm 2.3 \mathrm{~mm}, \mathrm{p}=0.0628)$ than the female patients. This can be explained by the fact that the male patients were significantly younger than the female patients (mean age $54.8 \pm 12.5$ vs $66.7 \pm 10.5$ years, $\mathrm{p}=0.0000$ ) because it has been well demonstrated that there is an inverse relation between left ventricular wall thickness and age in $\mathrm{HCM} !^{13}$ Our results are also consistent with other published studies, which demonstrated statistically significant thicker IVS and LVPW in youthful patients with HCM than in the elderly 14,15 In fact, after adjustment for age, we found that the difference in IVSt became statistically insignificant $(\mathrm{p}=0.1948)$.

\section{Systolic Anterior Movement of the Mitral Valve (SAM)}

In elderly patients with HCM, the mild hypertrophy of the left ventricle is generally confined to the septum, giving the left ventricular cavity an elliptical shape and the SAM appears less pronounced than in youthful patients with $\mathrm{HCM}$, in whom a crescent-shaped left ventricular cavity and a reversed curvature of the interventricular septum predominates and the SAM appears more commonly!4,15 Our study results of significantly more SAM in male than female patients (78.3 vs $47.4 \%, p=0.0008)$ can be accounted for, at least in part, by the age differential between the present male and female patients. After adjustment for age, we found that the difference in the prevalence of SAM became marginally significant $(\mathrm{p}=0.0670)$. Therefore, whether gender plays an additional role in the prevalence of SAM remains to be determined.

\section{Giant T Wave Inversion}

Classical cases of apical HCM associated with giant T wave inversions on ECG are exceeding rare outside Japan!6,17 Because we selected only cases with asymmetrical septal hypertrophy and an outflow gradient, none of our patients had isolated apical hypertrophy of the left ventricle. Therefore, the different prevalence of giant $\mathrm{T}$ inversions of male and female patients may represent the degree of left ventricular hypertrophy, or is related to IHD, both of which are more prevalent and pronounced in male patients than in female patients. The exact mechanism remains unclear.

\section{Ischemic Heart Disease (IHD)}

Recent studies have shown significant gender differences in coronary heart disease ${ }^{18,19}$ Death due to IHD occurs 5-10 years later in women than in men ${ }^{20}$ The lower prevalence of IHD in women can be partially attributed to risk factors such as lipid profiles $2^{20}$ smoking $2{ }^{2}$ and the probable protective effects of estrogen ${ }^{22}$ Our study showed that, although the male patients with HCM were younger, they had significantly more IHD than the female patients. Thus, the gender differences of IHD prevail even in the presence of HCM.

\section{Hypertension}

In our study population, the prevalence of hypertension was significantly higher among female patients than male patients. There are several possible explanations: First, the female patients were significantly older than the male patients and the prevalence of hypertension tends to rise with age ${ }^{23}$ Second, according to a national survey in the $\mathrm{USA}^{23}$ the prevalence of hypertension in men is greater than in women at ages under 65 ; however, the prevalence of hypertension in women exceeds that of men at ages over 65 . In the present study, the female patients had a mean age of 66.7 years as compared with the male patients' 54.8 years and this might account for the difference. Third, in a small subset of patients, predominantly elderly females, 
Table 3 Mean Age and Gender Predominance Among Studies of Hypertrophic Cardiomyopathy

\begin{tabular}{|c|c|c|c|c|}
\hline & No. of Patients & Follow-up (years) & Mean age (years) & $\%$ Male $(\%)$ \\
\hline Shah et $a l^{32}$ & 190 & 5.2 & 33.6 & 60 \\
\hline McKenna et al ${ }^{2}$ & 254 & 6 & 34 & 59.8 \\
\hline Maron et al ${ }^{33}$ & 99 & 3 & 38 & 75.8 \\
\hline Romeo et al ${ }^{4}$ & 125 & 7.6 & 34 & 63.2 \\
\hline Seiler et al ${ }^{34}$ & 139 & 10.3 & 37 & 81.3 \\
\hline Kofflard et al ${ }^{35}$ & 113 & 7.3 & 37 & 53.1 \\
\hline Spirito et al ${ }^{36}$ & 25 & 4.4 & 44 & 68 \\
\hline Fananapazir et al ${ }^{37}$ & 230 & 2.3 & 39 & 57 \\
\hline Yoshida et al ${ }^{38}$ & 83 & 6.7 & 51.2 & 79.5 \\
\hline Koga et $a l^{3}$ & 314 & 5 & 42 & 72.9 \\
\hline Cannan et al ${ }^{39}$ & 37 & 7.7 & 59 & 43 \\
\hline Lewis et al ${ }^{40}$ & 52 & 3.4 & 69 & 13 \\
\hline Fay et al ${ }^{28}$ & 95 & 4.2 & 71.8 & 39 \\
\hline Present study & 122 & 2.2 & 61.5 & 35.9 \\
\hline
\end{tabular}

Table 4 Differences of Mean Age Between Male and Female Patients With HCM

\begin{tabular}{|c|c|c|c|c|c|c|c|c|}
\hline & \multirow{2}{*}{$\begin{array}{l}\text { Patients } \\
\text { Number }\end{array}$} & \multirow{2}{*}{$\begin{array}{c}\text { Obstructive } \\
\text { (\%) }\end{array}$} & \multirow{2}{*}{$\begin{array}{c}\% \text { Male } \\
(\%)\end{array}$} & \multicolumn{5}{|c|}{ Mean Age (years) } \\
\hline & & & & Total & Male & Female & Diff.* & p-value \\
\hline Frank $^{l}$ (Familial) & 40 & 80 & 55 & 26.8 & 20.0 & 35.1 & 15.1 & $<0.01$ \\
\hline Frank $^{l}$ (Sporatic) & 86 & 80 & 72 & 32.7 & 29.3 & 41.3 & 12.0 & $<0.001$ \\
\hline Motamed $^{41}$ ( $>40$ year $)$ & 100 & $(-)$ & 43 & 56.9 & 53.5 & 59.5 & 6.0 & $(-)$ \\
\hline Level $^{14}$ & 56 & 70 & 66 & 49 & 44.6 & 57.5 & 12.9 & $(-)$ \\
\hline Dimitrow $^{12}$ & 94 & $(-)$ & 59 & $(-)$ & 26.7 & 31.3 & 4.6 & $<0.05$ \\
\hline Present study & 122 & 100 & 35.9 & 61.5 & 54.8 & 66.7 & 11.9 & $<0.001$ \\
\hline
\end{tabular}

Abbreviation: (-) data not available. *difference between male and female mean age.

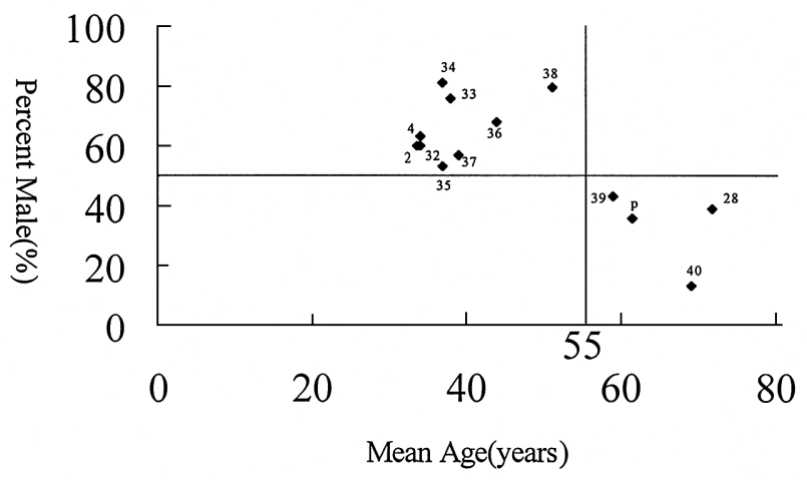

Fig 1. Mean age and male percentage of the study population. *Numbers in the graph refer to reference numbers in the text, $p$ is the present study.

hypertension has been demonstrated to cause severe concentric hypertrophy of the left ventricle, a small ventricular cavity, and supernormal indexes of systolic function? 4 Patiemts can even present with left ventricular outflow obstructions similar to that seen in HCM25,26 But most believe that hypertension is not the primary cause of HCM although it may coexist with or aggravate HCM24,27,28 In our study, the high prevalence of hypertension among female patients maybe due to one, 2 or all of aforementioned factors.

\section{Age Differences}

The most striking finding of the present study is the age differential between the male and female patients. There is evidence of the impact of gender on the development of many disease processes. Men tend to develop symptoms of schizophrenia 5 years earlier, 29,30 but develop symptoms of rheumatoid arthritis 5 years later than women 31 In review- ing the literature, we also found that men appear to develop symptoms of HCM or are diagnosed to have HCM earlier than women. As listed in Table 3, most published reports on HCM showed a male predominance $(>50 \%)$ in the young population (mean age $<55$ years) ${ }^{2-4,32-38}$ and a female predominance in the elderly population (mean age $>55$ years), ${ }^{28,39,40}$ as demonstrated in Fig 1 . And, as listed in Table 4, women appear to present with HCM 5-15 years later than their male counterparts!,12,14,41 In other studies, it was found that HCM in the elderly appeared to be a subset with distinctive left ventricular morphology and female predominance. They have a relatively small heart, an ovoid left ventricular cavity contour, a reduced left ventricular outflow tract, anterior displacement of the mitral valve and sizable deposits of calcium in the region of the mitral annulus ${ }^{14,40}$ They generally have a favorable prognosis 28 These studies, and the present data, suggest that gender may play an important role in the natural development, presentation, and progression of HCM. There are several possible explanations for the apparent difference. First, female patients may tend to seek medical attention later than their male counterparts. Second, HCM in the elderly may be the result of a different pathologic process from that active in younger patients, one that begins during or before middle age, yet is compatible with long life and this process affects females predominantly. Third, it may represent a gender-specific end organ response to the same disease process because growth, aging, systemic hypertension and coronary artery disease, etc. can affect quite differently male or female patients with the same genetic background. In the original study of Frank and Braunwald, males were significantly younger than females in both the familial and sporadic forms of the disease (Av. $=20.0$ years vs 35.1 years in the familial and Av. $=29.3$ years vs 41.3 years in the sporadic group). Kitzman et al reported 
that the mean value of indexed heart weights increased significantly in woman between the 3rd and 10th decades of life $(\mathrm{p}<0.01)$ and yet remain relatively constant with time in men 42 In aortic stenosis, with chronic left ventricular pressure overload, female patients develop more marked concentric hypertrophy, lower levels of wall stress, and higher indices of systolic function than their male counterparts9,43,44 These studies tend to favor the explanation that the age difference seen in male and female patients with HCM represents the gender-specific end organ response to aging and the underlying disease process. Dimitrow et al's postulation that endogenous estrogen may delay the development of HCM in females as compared with males is quite interesting! ${ }^{2}$ The exact mechanisms of estrogen's cardiovascular protective effects remain unclear, but estrogen's favorable effects on circulating lipoproteins ${ }^{20}$ its calcium-channel blocking properties ${ }^{45-49}$ and the effect on endothelium-derived relaxing factors ${ }^{50-52}$ have been postulated to play important roles. Further studies are needed, particularly longitudinal studies of patients with documented genetic aberration, as well as studies of the cardiovascular effects of estrogen, to clearly elucidate the impact of gender and estrogen on the natural course of HCM and the mechanism of the different progression patterns among male and female patients.

\section{References}

1. Frank S, Braunwald E: Idiopathic hypertrophic subaortic stenosis: clinical analysis of 126 patients with emphasis on the natural history. Circulation 1968; 37: 759-788

2. McKenna WJ, Deanfield JE, Faroqui A, England D, Oakley C, Goodwin JF: Prognosis in hypertrophic cardiomyopathy: role of age and clinical, electrocardiographic and hemodynamic features. Am J Cardiol 1981; 47: 532-538

3. Koga Y, Ogata M, Kihara K, Tsubaki K, Toshima H: Sudden death in hypertrophic and dilated cardiomyopathy. Jpn Circ J 1989; 53: $1546-1556$

4. Romeo F, Pelliccia F, Cristofani R, Martuscelli E, Reale A: Hypertrophic cardiomyopathy: is a left ventricular outflow tract gradient a major prognostic determinant? Eur Heart J 1990; 11: 233 240

5. Chiang CW, Lin FC, Fang BR, Kuo CT, Cherng WC, Lee YS: Doppler echocardiographic findings in healthy Chinese adults. $J$ Formos Med Assoc 1989; 88: 772-777

6. Sahn DJ, DeMaria A, Kisslo J, Weyman A: Recommendations regarding quantitation in M-mode echocardiography: results of a survey of echocardiographic measurements. Circulation 1978; 58: $1072-1083$

7. Brugada R, Kelsey W, Lechin M, Zhao G, Yu QT, Zoghbi W, et al: Role of candidate modifier genes on the phenotypic expression of hypertrophy in patients with hypertrophic cardiomyopathy. $J$ Investig Med 1997; 45: 542-551

8. Russell JW, Biller J, Hajduczok ZD, Jones MP, Kerber RE, Adams HP Jr: Ischemic cerebrovascular complications and risk factors in idiopathic hypertrophic subaortic stenosis Stroke 1991; 22: 1143 1147

9. Aurigemma GP, Gaasch WH: Gender differences in older patients with pressure-overload hypertrophy of the left ventricle. Cardiology 1995; 86: $310-317$

10. Pelliccia A, Maron BJ, Culasso F, Spataro A, Caselli G: Athlete's heart in women: Echocardiographic characterization of highly trained elite female athletes. JAMA 1996; 276: 211-215

11. Maron BJ, Thompson PD, Puffer JC, McGrew CA, Strong WB, Douglas PS, et al: Cardiovascular preparticipation screening of competitive athletes: A statement for health professionals from the Sudden Death Committee (clinical cardiology) and Congenital Cardiac Defects Committee (cardiovascular disease in the young), American Heart Association. Circulation 1996; 94: 850-856

12. Dimitrow PP, Czarnecka D, Jaszcz KK, Dubiel JS: Sex differences in age at onset of symptoms in patients with hypertrophic cardiomyopathy. J Cardiovasc Risk 1997; 4: 33-35

13. Spirito P, Maron MJ: Relation between extent of left ventricular hypertrophy and age in hypertrophic cardiomyopathy. $J$ Am Coll
Cardiol 1989; 13: 820-823

14. Lever HM, Karam RF, Currie PJ, Healy BP: Hypertrophic cardiomyopathy in the elderly: distinctions from the young based on cardiac shape. Circulation 1989; 79: 580-589

15. Lewis JF, Maron BJ: Clinical and morphologic expression of hypertrophic cardiomyopathy in patients $>65$ years of age. Am J Cardiol 1994; 73: 1105-1111

16. Maron BJ: Apical hypertrophic cardiomyopathy: the continuing saga. J Am Coll Cardiol 1990; 15: 91-93

17. Louie EK, Maron BJ: Apical hypertrophic cardiomyopathy: clinical and two-dimensional echocardiographic assessment. Ann Int Med 1987; 106: 663-670

18. Villablanca AC: Coronary heart disease in women: gender differences and effects of menopause. Postgrad Med 1996; 100: 191-196, $201-202$

19. Fetters JK, Peterson ED, Shaw LJ, Newby LK, Califf RM: Sexspecific differences in coronary artery disease risk factors, evaluation, and treatment: have they been adequately evaluated? Am Heart $J$ 1996; 131: 796-813

20. LaRosa JC: Dyslipoproteinemia in women and the elderly. Med Clin N Am 1994; 78: $163-180$

21. Waldron I: The contribution of smoking to sex differences in mortality. Public Health Rep 1986; 101: 163-173

22. Barrett-Connor E, Bush TL: Estrogen and coronary heart disease in women. JAMA 1991; 265: 1861-1867

23. Subcommittee on Definition and Prevalence of the 1984 Joint National Committee. Hypertension prevalence and the status of awareness, treatment, and control in the United States: Final report of the Subcommittee on Definition and Prevalence of the 1984 Joint National Committee. Hypertension 1985; 7: 457-468

24. Topol EJ, Traill TA, Fortuin NJ: Hypertensive hypertrophic cardiomyopathy of the elderly. N Engl J Med 1985; 312: 277-283

25. Pearson AC, Gudipati CV, Labovitz AJ: Systolic and diastolic flow abnormalities in elderly patients with hypertensive hypertrophic cardiomyopathy. J Am Coll Cardiol 1988; 12: 989-995

26. Faber L, Heemann A, Surig M, Michalowski Z, Gleichmann U, Klempt HW: Outflow acceleration assessed by continuous-wave Doppler echocardiography in left ventricular hypertrophy: an analysis of 103 consecutive cases. Cardiology 1998; 90: 220-226

27. Karam R, Lever HM, Healy BP: Hypertensive hypertrophic cardiomyopathy or hypertrophic cardiomyopathy with hypertension? A study of 78 patients. J Am Coll Cardiol 1989; 13: 580-584

28. Fay WP, Taliercio CP, Ilstrup DM, Tajik AJ, Gersh BJ: Natural history of hypertrophic cardiomyopathy in the elderly. $\mathrm{J} \mathrm{Am} \mathrm{Coll}$ Cardiol 1990; 16: 821-826

29. Hafner H, Maurer K, Loffler W, Riecher-Rossler A: The influence of age and sex on the onset and early course of schizophrenia. $\mathrm{Br} \mathrm{J}$ Psychiatry 1993; 162: 80-86

30. Loranger AW: Sex difference in age at onset of schizophrenia. Arch Gen Psychiatry 1984; 41: 157-161

31. Goemaere S, Ackerman C, Goethals K, De Keyser F, Van der Straeten C, Verbruggen G, et al: Onset of symptoms of rheumatoid arthritis in relation to age, sex and menopausal transition. $J$ Rheumatol 1990; 17: 1620-1622

32. Shah PM, Adelman AG, Wigle ED, Gobel FL, Burchell HB, Hardarson T, et al: The natural (and unnatural) history of hypertrophic obstructive cardiomyopathy. Circ Res 1974; 35(Suppl II): $179-195$

33. Maron BJ, Savage DD, Wolfson JK, Epstein SE: Prognostic significance of 24-hour ambulatory electrocardiographic monitoring in patients with hypertrophic cardiomyopathy: a prospective study. Am J Cardiol 1981; 48: 252-257

34. Seiler C, Jenni R, Vassalli G, Turina M, Hess OM: Left ventricular chamber dilatation in hypertrophic cardiomyopathy: related variables and prognosis in patients with medical and surgical therapy. $\mathrm{Br}$ Heart J 1995; 74: 508-516

35. Kofflard MJ, Waldstein DJ, Vos J, ten Cate FJ: Prognosis in hypertrophic cardiomyopathy observed in a large clinic population. Am J Cardiol 1993; 72: 939-943

36. Spirito P, Chiarella F, Lorenzo C, Berisso MZ, Bellotti P, Vecchio C: Clinical course and prognosis of hypertrophic cardiomyopathy in an outpatient population. N Engl J Med 1989; 320: 749-755

37. Fananapazir L, Chang AC, Epstein SE, McAreavey D: Prognostic determinants in hypertrophic cardiomyopathy: Prospective evaluation of a therapeutic strategy based on clinical, Holter, hemodynamic, and electrophysiological findings. Circulation 1992; 86: $730-740$

38. Yoshida M, Nakamura Y, Fukuhara T, Higashikawa M, Okada M, Shichiri G, et al: Prognostic determinants of hypertrophic cardiomyopathy: the results of the Shiga Cardiomyopathy Study. Jpn Circ J 
1995; 59: 745-753

39. Cannan CR, Reeder GS, Bailey KR, Melton LJ 3rd, Gersh BJ: Natural history of hypertrophic cardiomyopathy: A population-based study, 1976 through 1990. Circulation 1995; 92: 2488-2495

40. Lewis JF, Maron BJ: Elderly patients with hypertrophic cardiomyopathy: a subset with distinctive left ventricular morphology and progressive clinical course late in life. J Am Coll Cardiol 1989; 13: $36-45$

41. Motamed HE, Roberts WC: Frequency and significance of mitral annular calcium in hypertrophic cardiomyopathy: analysis of 200 necropsy patients. Am J Cardiol 1987; 60: 877-884

42. Kitzman DW, Scholz DG, Hagen PT, Ilstrup DM, Edwards WD: Age-related changes in normal human hearts during the first 10 decades of life. Part II (Maturity): A quantitative anatomic study of 765 specimens from subjects 20-99 years old. Mayo Clin Proc 1988; 63: $137-146$

43. Aurigemma GP, Silver KH, McLaughlin M, Mauser J, Gaasch WH: Impact of chamber geometry and gender on left ventricular systolic function in patients $>60$ years of age with aortic stenosis. Am J Cardiol 1994; 74: 794-798

44. Villari B, Campbell SE, Schneider J, Vassalli G, Chiariello M, Hess OM: Sex-dependent differences in left ventricular function and structure in chronic pressure overload. Eur Heart J 1995; 16: 1410-1419

45. Jiang C, Poole-Wilson PA, Sarrel PM, Mochizuki S, Collins P, MacLeod KT: Effect of 17beta-oestradiol on contraction, $\mathrm{Ca}^{2+}$ current and intracellular free $\mathrm{Ca}^{2+}$ in guinea-pig isolated cardiac myocytes. Br J Pharmacol 1992; 106: 739-745
46. Jiang C, Sarrel PM, Lindsay DC, Poole-Wilson PA, Collins P: Endothelium-independent relaxation of rabbit coronary artery by 17beta-oestradiol in vitro. Br J Pharmacol 1991; 104: 1033-1037

47. Stice SL, Ford SP, Rosazza JP, Van Orden DE: Role of 4-hydroxylated estradiol in reducing $\mathrm{Ca}^{2+}$ uptake of uterine arterial smooth muscle cells through potential-sensitive channels. Biol Reprod 1987; 36: $361-368$

48. Ogata R, Inoue Y, Nakano H, Ito Y, Kitamura K: Oestradiol-induced relaxation of rabbit basilar artery by inhibition of voltage-dependent Ca channels through GTP-binding protein. Br J Pharmacol 1996; 117: $351-359$

49. Collins P, Beale CM, Rosano GM: Oestrogen as a calcium channel blocker. Eur Heart J 1996; 17(Suppl D): 27-31

50. Reis SE, Gloth ST, Blumenthal RS, Resar JR, Zacur HA, Gerstenblith G, et al: Unstable plaques, endothelial dysfunction, and coronary artery thrombosis: ethinyl estradiol acutely attenuates abnormal coronary vasomotor responses to acetylcholine in postmenopausal women. Circulation 1994; 89: 52-60

51. Gilligan DM, Quyyumi AA, Cannon RO III, Johnson GB, Schenke WH: Atherosclerosis/coronary heart disease: effects of physiological levels of estrogen on coronary vasomotor function in postmenopausal women. Circulation 1994; 89: 2545-2551

52. Kawano H, Motoyama T, Kugiyama K, Hirashima O, Ohgushi M, Fujii $\mathrm{H}$, et al: Gender difference in improvement of endotheliumdependent vasodilation after estrogen supplementation. J Am Coll Cardiol 1997; 30: 914-919 